\title{
Selective deficits in cognition and memory in high-functioning Parkinsonian patients
}

\author{
Erich Mohr, Jorge Juncos, Christiane Cox, Irene Litvan, Paul Fedio, Thomas N Chase
}

\begin{abstract}
To evaluate the profile and extent of cognitive deficits in Parkinson's disease, afflicted patients of exceptional professional distinction, who continue to function successfully in leadership positions, were compared neuropsychologically to neurologically normal individuals, matched for sex, age, education and professional standing. While patients showed relative preservation of verbal skills and higher executive function, they exhibited a significant reduction in episodic memory and visuospatial function. The observation of circumscribed impairment in this select group of Parkinsonian patients further implicates cognitive and memory deficits as consistent features of Parkinson's disease.
\end{abstract}

Parkinson's disease, characterised originally as a motor disorder with "senses and intellect uninjured", ${ }^{1}$ has received increasing attention for its cognitive concomitants..$^{2-7}$ Reported intellectual deficits have ranged from relatively specific changes in visuospatial cognition $^{8}$ to the occurrence of global dementia. ${ }^{9}{ }^{10}$ Factors suggested as possibly contributing to the appearance of these deficits include deficiencies related to motor disturbance, agerelated cognitive decline, inability to maintain attention due to being easily fatigued and distraction by pain and dyskinesia. ${ }^{11}$ In addition, sedation, confusion and other druginduced adverse effects ${ }^{11}$ as well as additional disease processes like Alzheimer's disease, may affect intellectual integrity. Thus, it may be difficult to ascribe compromises in cognition and memory in an otherwise unselected Parkinsonian population exclusively to the pathophysiology of this disease.

In an attempt to address this question, we studied Parkinsonian patients selected from a group who sought medical assistance solely for the management of their motor dysfunction. Each was of exceptional professional standing, continued to function successfully in his or her premorbid occupation and showed no evidence of global dementia (Mattis Dementia Rating Scale). ${ }^{12}$ None indicated awareness of any cognitive impairment or difficulty with professional endeavours. After a complete neurological examination and adjustment of their anti-Parkinsonian medication, all patients had a detailed neuropsychological examination, with emphasis on executive function, memory and visuospatial skills.

\section{Methods}

Ten patients (eight men and two women, mean (SEM) age of 53 (2), range 43 to 62 years) with idiopathic Parkinson's disease, diagnosed on the basis of the presence of at least two of the three cardinal features (bradykinesia, rigidity and resting tremor) and the absence of any known cause of secondary Parkinsonism, took part in this experiment. Ten normal subjects (eight men and two women, age 53 (4), range 46 to 66 years) served as controls. All consented to participate in this study after full disclosure of potential risks and benefits. Parkinsonian patients were selected from a much larger group of potential study subjects on the basis of their ability to maintain senior level employment in positions demanding a relatively high level of intellectual competency (for example, corporate executives, senior government official, university professors) as well as absence of documentable dementia (Mattis Dementia Rating Scale; table). At the time of the study, three required no anti-Parkinsonian therapy; the remaining seven individuals were well controlled with standard dopaminomimetic agents. None evidenced any clinically significant adverse effects of their therapeutic regimen. Parkinsonian symptoms had been present on the average for eight years (range 1 to 17 years), and were mild to severe while medicated ( 1 to 4 on the modified Hoehn and Yahr scale), with one patient in stage 1 , two in stage 2 , four in stage 3 , three in stage $4 .{ }^{13}$

Control subjects were matched for sex, age, education and comparable professional standing and were also free of dementia (Mattis Dementia Rating Scale; table) or other neurological impairment.

Patients' motor status at the time of cognitive testing was evaluated with a modified version of the Columbia Rating Scale (table). Intellectual and memory function was assessed with the Wechsler Adult Intelligence Scale-Revised (WA1S-R) (44 $^{14}$ and with the Wechsler Memory Scale. ${ }^{15}$ In addition, the following neuropsychological tests were administered to examine executive function, memory and visuospatial skills: Wisconsin Card Sorting Test $;^{16}$ a modified version of the Ego State Inventory ${ }^{17}$ to assess correct judgment of social situations; Benton Visual Retention Test; ${ }^{18}$ Rey-Osterrieth Figure; ${ }^{19} 20$ Mosaics Comparison Test, ${ }^{21}$ and Embedded Figures Test. ${ }^{22}$ All tests were given without time limits and inaccuracies related to tremor were ignored. The patients' mood state was assessed with the Beck Depression Inventory. ${ }^{23}$ Data were analysed with standard 
Table Subject characteristics, with intellectual and memory profiles

\begin{tabular}{|c|c|c|c|c|c|c|}
\hline & \multicolumn{3}{|c|}{ Normal Controls $(N=10)$} & \multicolumn{3}{|c|}{ High Functioning Parkinsonian patients $(N=10)$} \\
\hline & Mean & $(S E M)$ & Range & Mean & (SEM) & Range \\
\hline $\begin{array}{l}\text { Age } \\
\text { Education } \\
\text { Duration of illness } \\
\text { Hoehn and Yahr Stage } \\
\text { Columbia Rating Scale } \\
\text { Verbal IQ } \\
\text { Performance IQ } \\
\text { Full Scale IQ } \\
\text { Memory Quotient } \\
\text { Mattis Dementia Rating Scale } \\
\text { Beck Depression Inventory }\end{array}$ & $\begin{array}{r}133 \\
125 \\
133 \\
138 \\
142 \\
3\end{array}$ & $\begin{array}{l}(2.9) \\
(3.6) \\
(3.3) \\
(2.6) \\
(0.9) \\
(1.3)\end{array}$ & $\begin{array}{c}(121-146) \\
(105-144) \\
(124-145) \\
(116-143) \\
(136-144) \\
(0-9)\end{array}$ & $\begin{array}{r}53 \\
19 \\
7 \\
3 \\
21 \\
126 \\
103 \\
117 \\
119 \\
140 \\
11\end{array}$ & $\begin{array}{l}(2 \cdot 1) \\
(0 \cdot 6) \\
(1 \cdot 7) \\
(0 \cdot 3) \\
(3 \cdot 9) \\
(3 \cdot 5) \\
(4 \cdot 6) \\
(4 \cdot 1) \\
(6 \cdot 0) \\
(1 \cdot 4) \\
(1 \cdot 8)\end{array}$ & $\begin{array}{l}(44-62) \\
(16-20) \\
(1-17) \\
(1-4) \\
(9-44) \\
(112-144) \\
(86-129)^{\star} \\
(102-140)^{\star} \\
(92-143)^{\star} \\
(130-144) \\
(4-21)^{\star}\end{array}$ \\
\hline
\end{tabular}

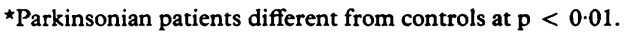

analysis of variance procedure ${ }^{24}$ and where appropriate, with correlational measures. ${ }^{25}$

\section{Results}

Evaluation of patients' overall intellectual function revealed significant reductions in the Full Scale intelligence quotient (IQ), primarily due to differences in the Performance IQ of the WAIS-R (both $p<0.01$, table). In contrast, their verbal aptitude was relatively retained at a superior level, reflected in comparable Verbal IQ levels in the patient and control group.

Executive function appeared uncompromised in the Parkinsonian patients. The Wisconsin Card Sorting Test, both the Initiation and the Conceptualisation subtest of the Mattis Dementia Rating Scale, and the Mental Control subtest of the Wechsler Memory Scale revealed no functional decrement in the patients $(\mathrm{p}>0 \cdot 2$, fig (a)). Patients also performed similarly to controls on the Ego State

Figure

Neuropsychological task performance.

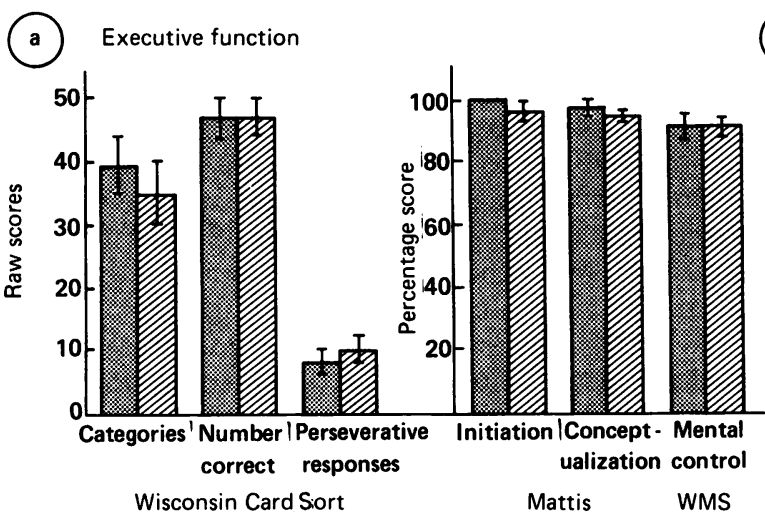

Inventory [Scores (SEM): multiple choice: patients 191 (2), controls 204 (3); self rating: patients $184(6)$, controls $186(3), p>0 \cdot 1)$ ].

Tests of memory function, on the other hand, demonstrated substantial decline in those with Parkinson's disease. Global scores (memory quotients, Wechsler Memory Scale) were significantly reduced $(p<0.01$, table) reflecting deficits on certain subtests. Patients recalled significantly fewer items than controls on the Logical Memory Test, both during immediate and delayed recall ( $\mathrm{p}<0.05)$, but performed comparably to controls on Paired Associate Learning ( $p>0.09$, fig (b)). Visuospatial memory indicated a similar profile. Both the Visual Reproduction subtest of the Wechsler Memory Scale and percentage loss of the Rey-Osterrieth Complex Figure reproduction from copy to three minutes recall, showed consistent deficits in the Parkinsonian patients ( $p<0.01 ; p<0.001$; fig (c)). Simple visuospatial stimuli (Benton Visual Retention

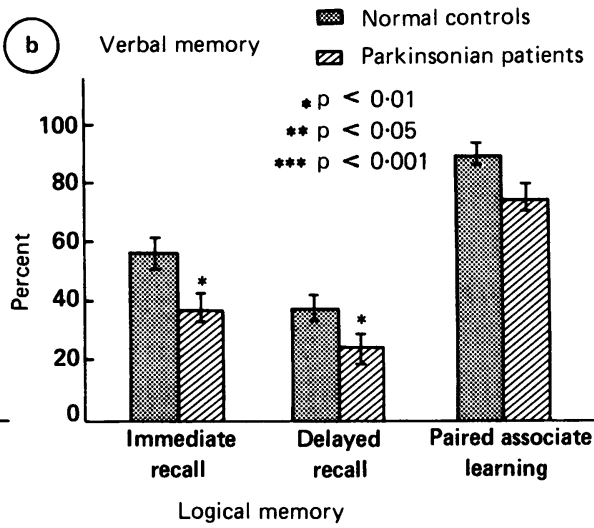

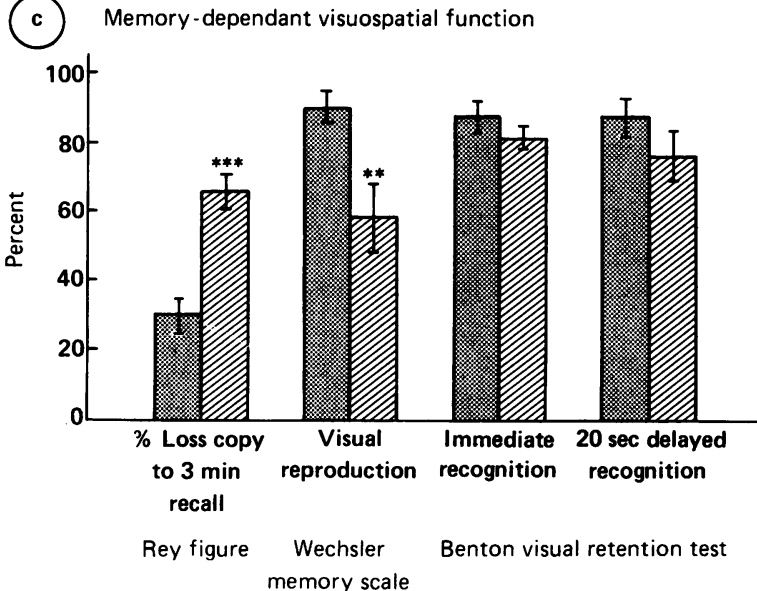

(d)

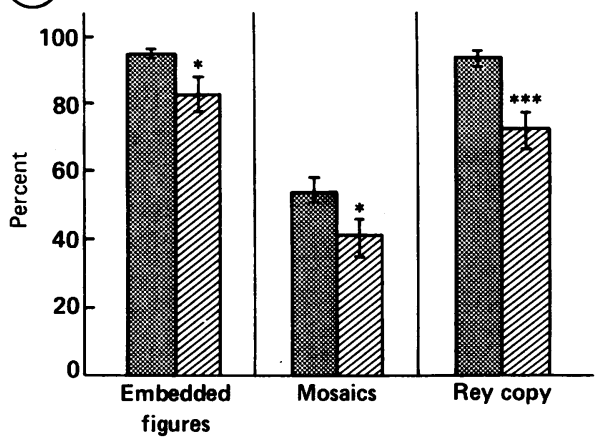


Test), on the other hand were identified as well by patients as by controls, both on immediate and on delayed recognition ( $p>0 \cdot 2$, fig (c)).

Memory independent visuospatial function also evidenced some decline in the Parkinsonian group. Tasks involving copying a complex figure (Rey-Osterrieth Figure), the selective identification of complex visual patterns (Mosaics) as well as visual disembedding (Embedded Figures) were significantly less accurately performed by patients compared with controls ( $p<0.001$, Rey-Osterrieth Figure; $p<0.05$, Mosaics and Embedded Figures; fig (d)).

The Beck Depression Inventory indicated significantly higher scores in the patient compared with the control group (table); however, neither group fulfilled criteria for the clinical diagnosis of depression. ${ }^{23}$

Correlation of patients' motor disability scores (Hoehn and Yahr stage and overall Columbia rating score), symptom duration, length of treatment and Beck Depression Inventory, with neuropsychological test scores, failed to reveal any significant relationship.

\section{Discussion}

The present study assessed intellectual function in idiopathic Parkinson's disease through the application of a selected battery of neurobehavioural tests to a subset of patients deemed relatively unlikely to manifest neuropsychological deficits. Our finding of compromised intellectual and memory performance even in this group of high functioning individuals, supports the notion that cognitive impairment may indeed be a consistent feature of this disease.

Nevertheless, cognitive decrements in this group of patients were selective. High functioning Parkinsonian patients appear to retain most of their premorbid verbal abilities (VIQ), but evidence substantially compromised visuospatial function (PIQ), a frequent pattern in otherwise nonselected, non-demented Parkinsonian individuals. ${ }^{26}$ Selectively lowered Performance IQs may be attributable, at least in part to the motor deficits of these patients. The preservation of executive function in patients was rather more surprising, since such abnormalities have frequently been reported. ${ }^{626}$ While selection criteria employed in this study probably contributed to this result, it is noteworthy that there are individuals with Parkinson's disease without such deficits. Tasks such as the Wisconsin Card Sorting Test ${ }^{16}$ considered to rely on internal control, ${ }^{11}$ have consistently been reported as impaired in Parkinsonian patients. ${ }^{6126}$ Although it might be argued that our patients showed no deficit on this test due to the careful attention to optimisation of treatment, previous results show evidence for impaired function both when "on" and "off" and recent reports of improved function on neuropsychological tasks with dopaminomimetic treatment tend to be small and highly selective. ${ }^{27} 28$

Patients in this study did, however, show selective deficits in memory function, both verbally as well as visuospatially mediated. While several of the currently available memory models may be useful for the study of this deficit in Parkinson's disease, the notion of involvement of effort demanding episodic memory ${ }^{2930}$ has gained particular attention. ${ }^{27}{ }^{28}$ Parkinsonian patients evidenced patterns of functional compromise which could also be differentiated along the axis of effort; the more effort demanding memory tasks evidenced impairments relative to control subjects, while simplier items classified patients within the normal range. In an attempt to evaluate the contribution of memory decrements in visuospatial cognition, memory independent tasks of visuospatial integration were introduced. Results showed the same pattern: complex tasks showed impairment while simpler ones showed relatively preserved function.

Recent neuroanatomical evidence may be helpful in explaining certain aspects of the differential functional impairments noted here. The bipartite model of basal ganglia frontal cortex connectivity involving a motor and a complex loop, ${ }^{32}$ has recently been augmented by suggestions of a more complicated division of striatal frontal connections of five or even more circuits. ${ }^{33}$ Thus in addition to two motor circuits, a dorsolateral prefrontal-, a lateral orbitofrontal- and an anterior cingulate circuit have been proposed. ${ }^{33}$ While any functional definition still remains uncertain, preclinical studies with primates have implicated the dorsolateral prefrontal circuit in certain aspects of spatial memory, while the lateral orbitofrontal circuit has tentatively been linked to the capacity to make appropriate switches in behavioural sets. ${ }^{33}$ Clinical studies, on the other hand, have maximally implicated the dorsolateral frontal areas in this type of executive ability. ${ }^{3435}$ Whatever the final outcome of this discussion, the differences in functional impairment observed here might be linked to differential pathology in striatal frontal connectivity.

Most reports to date seem to agree in implicating varying degrees of frontal lobe involvement in Parkinson's disease, with increasingly refined methods of defining the exact nature of this deficit. ${ }^{11}$ However, our evidence suggests that it is possible to identify a subset of Parkinsonian patients without neuropsychological evidence of dysfunction in this area. Nevertheless, even these patients suffered from impairments in visuospatial cognition and memory. Certain intellectual impairments may thus be a concomitant of the motor symptoms of this disorder, but do not necessarily include "executive function". Further functional definition of neural circuits involved in the pathophysiology of Parkinson's disease may allow for the development of potential treatment strategies of the cognitive deficits associated with this disorder.

1 Parkinson J. An essay on the shaking palsy. London: Sherwood, 1817

2 Brown RG, Marsden $C D$. Visuospatial function in Parkinson's disease. Brain 1986;109:987-1002. 
3 Elizan TS, Sroka H, Maker H, Smith H, Yahr MD. Dementia in idiopathic Parkinson's disease: variables
associated with its occurrence in 203 patients. $J$ Neural Transmission 1986;65:285-302.

4 Brown RG, Marsden CD. Neuropsychology and cognitive function in Parkinson's disease: An overview. In: Marsden $\mathrm{CD}$, Fahn S, eds. Movement disorders 2. London: Butterworths, 1987:99-123.

5 Taylor AE, Saint-Cyr JA, Lang AE, Kenny FT. Parkinson's disease and depression: A critical reevaluation. Brain 1986;109:279-92.

6 Taylor AE, Saint-Cyr JA, Lang AE. Frontal lobe dysfunction in Parkinson's disease. Brain 1986b;109:845-83.

7 Morris RG, Downes JJ, Sahakian B, Evenden JL, Heald A Robbins TW. Planning and spatial working memory in Parkinson's disease. J Neurol Neurosurg Psychiatry 1988;51:757-66.

8 Boller F, Passafiume D, Keefe N, Rogers K, Morrow L, Kim Y. Visuospatial impairment in Parkinson's disease: The role of perceptual and motor factors. Arch Neurol 1984;41:485-90.

9 Lieberman A, Dziatolowski M, Kupersmith $M$, et al. Dementia in Parkinson's disease. Ann Neurol 1979;6: 355-9.

10 Taylor AE, Saint-Cyr JA, Lang AE. Dementia prevalence in Parkinson's disease. Lancet 1985; 1 : 1037 .

11 Brown RG, Marsden CD. An investigation of the phenomenon of "set" in Parkinson's disease. Movement phenomenon of "set" in

12 Mattis S. Mental status examination for organic mental syndrome in the elderly. In: Bellack L, Karasu TB, eds. Geriatric Psychiatry. New York: Grune and Stratton, 1976:77-121.

13 Fahn S, Marsden CD, Calne D, Goldstein M. Recent developments in Parkinson's disease. New Jersey: Macmillan Health Care Information, 1987:293-304.

14 Wechsler D. Wechsler Adult Intelligence Scale-Revised. New York: The Psychological Corporation, 1981.

15 Wechsler D, Stone CP. Wechsler Memory Scale. New York: The Psychological Corporation, 1945.

16 Heaton R. Wisconsin Card Sorting Test Manual. Odessa, Florida: Psychological Assessment Resources, 1981.

17 McCarley DG. Ego State Inventory. Chicago: Stoelting Company, 1975

18 Benton AL, deHamsher K, Varney NR, Spreen $O$ Contributions to neuropsychological assessment: a clinical manual. New York: Oxford University Press, 1983

19 Rey A. L'examen psychologique dans le cas d'encephalopathie traumatique. Archives de Psychologie 1941;28.
286-340.

20 Osterrieth PA. Le test de copie d'une figure complexe: contribution l'etude de la perception et de la memoire. Archives de Psychologie 1944;30:206-356.

21 Mosaics Comparison Test. Comparative Guidelines and Placement Programs. Princeton, New Jersey: College Entrance Examination Board, ETS, 1972.

22 Kapur N, Butters N. Visuoperceptive deficits in long-term alcoholics and alcoholics with Korsakoff's psychosis. J Stud Alcohol 1977;38:2025-35.

23 Beck AT, Ward CH, Mendelson M, Mock J, Erbaugh J. An inventory for measuring depression. Arch Gen Psychiatry 1961;4:53-63.

24 Brown MD, Engelman L, Frane JW, Hill MA, Jennrich RI, Toporek JD. BMDP Statistical Software. Los Angeles: University of California, 1985:59-412.

25 Joyner SP. SAS User's Guide: statistics, 5 th ed. Cary, NC: SAS Institute Inc, 1985:827-9.

26 Gotham AM, Brown RG, Marsden CD. "Frontal" cognitive function in patients with Parkinson's disease "on" and "off" levodopa. Brain 1988;111:299-321.

27 Mohr E, Fabbrini G, Ruggieri S, Fedio P, Chase TN. Cognitive concomitants of dopamine system stimulation in Parkinson's disease. $J$ Neurol Neurosurg Psychiatry 1987;50:1192-6.

28 Mohr E, Fabbrini G, Williams J, et al. Dopamine and memory function in Parkinson's disease. Movement Dismemory function in

29 Weingartner H. Psychobiological determinants of memory failure. In: Squire L, Butters N, eds. Neuropsychology of Memory. New York: Guilford Press, 1984:203-12.

30 Weingartner H, Burns R, Diebel R, LeWitt PA. Cognitive impairments in Parkinson's disease: Distinguishing between effort-demanding and automatic cognitive processes. Psychiatry Res 1984;11:223-35.

31 Delis D, Direnfeld L, Alexander MP, Kaplan E. Cognitive fluctuations associated with the on-off phenomenon in Parkinson disease. Neurology 1982;32:1049-52.

32 DeLong MR, Georgopoulos AP, Crutcher MD. Corticobasal ganglia relations and coding of motor performance. Experimental Brain Res 1983;7:30-40.

33 Alexander GE, DeLong MR, Strick PL. Parallel organiza tion of functionally segregated circuits linking basal tion of functionally segregated circuits linking basa

34 Milner B. Effects of different brain lesions on card sorting The role of the frontal lobes. Arch Neurol 1963;9:90-100. 35 Milner B. Some effects of frontal lobectomy in man. In: Warren JM, Akert K, eds. The frontal granular cortex and behavior. New York: McGraw-Hill, 1964:313-34. 